\title{
16 Emerging Publics and Interventions in Democracy
}

\author{
Michael Krona and Måns Adler
}

Technological innovation, design, and development is often aimed at providing improvements for people and contribute to a progressive society, even though history tells us that fears of new technology are as common as the optimistic visions of the same. Discourses surrounding the development of radio, television, and the Internet have shared these dichotomous notions of what a new technology may portend. However, when the idea of democratizing live video broadcasting emerged and was implemented through Bambuser, visionary, idealistic, and optimistic notions set the tone. Bambuser was developed with the mission to democratize a technology that back in 2006 was available only to a lucky few. Innovative entrepreneurs with connections to the Malmö region shared the vision and realized the idea by aligning themselves with a strong Scandinavian heritage of participatory design. The focus was on the opportunity for citizens to broadcast live video from anywhere to anyone. At the time, only a major news corporation could afford a broadcasting van and transmit moving images. The vision was to see what happened if one could symbolically put a broadcasting van in everyone's pocket through the use of cellular phones and computers. In this chapter we enter the discourse of technological innovation through this type of visionary statements implemented in the design phase, but also through a critical notion of how this technology embraces a paradox in a societal context. When narrowed down to the political uprisings in the Middle East and North Africa in the years 2010-2013, this paradox surrounding media technology in general and the use of mobile communications and video broadcasting in particular can be witnessed in how both citizens and regimes use this technology in order to reach their respective objectives. These dimensions of access and use are vital parts of a rapidly evolving sousveillance society defining our time- - a time in which boundaries of private and public have been dissolved and power relations are in transition.

This chapter starts in the design phase of Bambuser, puts the service and the use of it in present-day theoretical frameworks and empirical cases from the Arab Spring, and concludes with a wider discussion on the role and implementation of this technology in the societal context of increasing transnational sousveillance. By exploring both 
design and innovation behind the case of Bambuser, it contributes to obtain new perspectives on the creation of public discourses and making public spaces a matter for not only privileged but emerging new publics as well.

\section{Digital divides, access, and social shaping of technology}

Voices on how democracy best can and should develop, revitalize, and progress are hardly few. On the contrary, forums for dialogue and debate hold a variety of approaches in community discussions, and citizens have, more than ever before, the opportunity to use media technology to participate in a progressive way in discourses of public concern (Dahlgren 2009). It would be no exaggeration to say that these discourses are largely created and re-created by the public. However, the global distribution of infrastructural resources is characterized by a major inequality; the participation mainly derives from a Western definition of democracy and freedom of speech, and media technology as means for participation is sometimes taken for granted. The expansive technological revolution that has characterized most Western societies during recent decades has created a digital divide in relation to developing countries (van Dijk 2005). The continents and nations that are not included in this rapid development still have a long way to go in terms of infrastructure and network capacity. But the question of access to media technology involves a lot more than aspects of technical infrastructure, for example media literacy, which also has implications for political subsidiaries and cultural dimensions that need to be integrated in attempts to grasp this digital divide. Hence, the divide is defined on the distance that gradually grows as Western economies are still largely dominant in trade and create the information society as we know it. It is also fair to acknowledge that policy makers around the world define this as a technological phenomenon rather than a social one. This becomes problematic when the issue is discussed only in relation to the distribution of infrastructural resources and not in relation to social, cultural, and political implications. Much of the research on digital divides has focused on access, or what Riggins and Dewan (2005) call "first order effects." Little attention has been given to second-order effects, such as inequality in the ability to use and fully comprehend the nature of the technology. In line with this, we argue for a view on the digital divide as first of all a social problem in which the technological aspect is highly integrated. And it is within this social divide that Bambuser can provide opportunities to significantly alter the structure of public spheres and bring marginalized groups of citizens closer to a deliberative state of opinion creation.

One of the key factors in trying to decrease the gap between the Western world and nations in more undeveloped regions is the use and control of technology. This issue has been highly debated during the Arab Spring in particular and the ongoing uprisings in North Africa and the Middle East (Lynch 2011). The intellectual debate has above all focused on the use of media technology in order to achieve social change in the region, 
in other words, the debate has approached the role of technology predominantly from the users' perspective. The participatory function of media design is central to a comprehension of present-day media ecology; an ecology of digital networks as well as traditional media outlets. In this chapter we focus on the digital networks and what we define as democratization of technology, or in more specific terms the democratization of the live video broadcast. Bambuser, which was developed for this idealistic purpose, can to a certain extent be considered an example of how the relation between humans and media technology can intervene with democracy more explicitly than any traditional mass- and personal media ever managed throughout history.

Design and innovation within technology and communications must always be put in a societal context, positioning the innovation itself as a part of socio-political realities. Discussions of the role of technology sometimes seem to take a rather simplified direction in which the tool itself (technology) is solely defined as the main contributor to social and political change (Hofheinz 2011). This notion is also a statement in a larger intellectual debate on theoretical points of departure between Diffusion of Innovations Theory (DIT) and the Social Shaping of Technology (SST). These two oppositional perspectives, which share roots in an interactionist tradition connected to the Chicago school of sociology, differ substantially when it comes to the actual human intervention and use of the technology. It is within this intersection that the perspectives take oppositional directions. In the terminology of Boczkowski (2004) they can be classified as mediated impact and shaping explanations of technological development, respectively. The basic notion in the perspective of SST is that "technological determinism is an inadequate description or explanation of technological innovation and development" (Lievrouw and Livingstone 2006, 248). To talk about the impact or effect of technology in society would, within this perspective, be to accept a technological determinism. Instead the spotlight is directed on the pragmatic human intervention and choices within technological development.

Hence, our argument here is that the use of technology could, and should, be seen as contributing to changes in peoples' awareness and notions of citizenship rather than simply being a tool for political change. It is not the technology that changes society; it is people who use the technology. This argument is in line with the historical research on mass media and opinion making conducted in 1948 by Elihu Katz and Paul Lazarsfeld, who concluded that the mass media alone did not change peoples' minds. Opinions, knowledge, and awareness can be transmitted through media, but family members and friends then echo them through personal interaction in physical life. In this second and social step, the opinions are formed; hence, this is the phase in which media technology in general and social media in particular can make a difference. The present blurring of the boundaries between consumption and production within the media sphere has created possibilities for alternative voices and marginalized groups of society. 


\section{Democratic aspects of designing and implementing Bambuser}

In the current construction of a new political modernity, citizens, through technology, gather around causes, shared values, and imagined communities in order to form opinions that opposes to the established structures that for decades have taught people how to be citizens (Howard 2011). This notion harmonizes with a perspective on design and innovation as a user-driven process with potentials in value production. In the case of Bambuser, the intersections between design of the service, use, and involvement as well as the societal context of implementation are important aspects of how to comprehend a democratization of technology.

Because Bambuser also is a service that derives from the Scandinavian tradition of participatory design, fundamentally as a result of challenging the use of technology and with ambitions to bring democracy and innovation closer together on several levels, it is adequate to theoretically frame this use toward a sociological trajectory of participatory communication (PC). Within the creation and implementation of PC processes, there are a number of principles that emerge as fundamental. Tufte and Mefalopulos (2009) discuss a number of these principles. In relation to Bambuser, two specific features of these discussions shed light on the user-driven design approach: (a) the creation of participatory spaces and (b) providing a voice to marginalized groups. Any society has gaps between social groups related to gender, ethnicity, religion, or class. Inclusion and exclusion in relation to public discourses and spheres is part of social life with or without technological development. However, when entering a critical discussion on innovation and design within communication and technology sectors, the question of access and inclusion becomes paramount. Access is not, and must not be viewed as, a matter of merely providing infrastructure through computers and Internet connections (Riggins and Dewan 2005). Accessibility also includes resources of physical, human, digital, and social nature. Education, literacy, and language all have to be taken into account when performing a societal analysis.

\section{Bambuser-materializing the vision}

Creating participatory spaces and platforms through community-based media, such as Bambuser or YouTube, can embrace progressive dialogue between individuals and groups. From this perspective, Bambuser can be viewed as a service with potential to provide an important arena for this dialogue (Löwgren and Reimer 2013). Access has in the design process been approached as a key concept regarding participation and stimulating dialogue. But as the design process evolved around the technical thresholds, there were two contextual dimensions that needed to be reflected upon: what people would choose to broadcast and what people would choose to watch. 
In order to comprehend these dimensions one must first consider present-day financial and market incentives. Incrementally, in more economic terms the vision of Bambuser was to reduce production costs for traditional broadcasting and make it practically free for citizens. When the service was set up, the price for a second of broadcasting was equivalent to several U.S. dollars. The amount of viewers could then be used to finance the costs by letting them be exposed to commercials or through national public broadcasting fees.

Analyses of emerging trends in the technical ecology soon led to a strategic choice to integrate and enable the mobile phone as a symbolic counterpart to the broadcasting van. Three major trends were important. First, the processing power in mobile phones would grow exponentially, making them able to compress the video material faster to achieve higher quality. Second, the bandwidth within cellular networks was expanding rapidly, providing increased bandwidth to the phones and enabling better real-time broadcasts. Finally, and perhaps most important, as the cellular networks would grow in bandwidth capacity the cost of sending a megabit of data would decrease as a result of market competition, resulting in a close to flat-rate price. These emerging trends, which could be foreseen from any contextual analysis on the subject, resulted in design work that focused on cell phones. As Rheingold (2002) argues, information technology, and mobile communication in particular, empowers smart mobs to gather, initiate, and execute political action with the help of the mobilizing function of media technology. In this respect it is important to remember that the idea of Bambuser arose in the era of the Nokia N95, before Androids, iPhones, and app stores. However, the later emergence of these devices and phenomena and the rapid development of smartphones all worked in favor of Bambuser (Löwgren and Reimer 2013).

In late 2007 the video platform of Bambuser was launched. It was similar to other video platforms, such as YouTube and Daily Motion, but with the difference of live content. Bambuser grew steadily in Europe, backed by Norwegian venture capital and a socalled "freemium" business model. Users produced different material, from little league soccer games and union press conferences. Some people attached mobile phones to radio-controlled model airplanes. Through a normative assumption of contributing with an open-ended extension of the public sphere, people's increased possibilities to take part in opinion-building lectures, ask questions in real time, and watch public companies arranging press conferences on their phones were soon to be more frequent in larger political and social development contexts. That, however, required a re-design process that involved the user to a greater extent than before. In the beginning the technological and usability aspects were very simple. A user could just start a broadcast and give it a title. But as the user experience was continuously evaluated, it soon became clear that increased user-oriented convergence was necessary. Functionalities such as embeddable players that users could put on their own blogs and Web pages 
were soon added. Demand for metadata increased, and through the use of titles and GPS positioning viewers were given the opportunity to browse between broadcasts as they went live. Hence, by providing features that extended the experience of combining live video broadcasting with user-generated content, the number of users increased rapidly and the first sense of importance in providing the technology with a social dimension emerged.

\section{Sharing the vision-social dimensions of the technology}

The social implications and effects of new media technology have been discussed widely within the fields of media and communication studies and sociology (see Thompson 1995; Briggs and Burke 2009; Chapman 2005). These contributions share a macro-sociological approach in discussing how the printing press, radio, and television generated transformations in social life. Throughout history, cultural traditions and leisure have been transformed and integrated with different forms of media development. These social aspects of media, however, are not necessarily connected to more detailed social dimensions concerning user involvement and distribution-taking the social dimension of media to the actual interaction with the technology and not just the sociocultural implications. In the case of interactivity as part of digital media and culture, online video broadcasting through Bambuser holds a more specific approach toward placing technology in a social context.

It is important here to separate the previously mentioned contributions of social implications of the emergence of new media from what is argued here, namely the importance of providing the service or technology with a social dimension. This dimension can then serve as a participatory trigger of authenticity, making the user aware of the live feature and also be a co-director of the broadcast. Early broadcasts on Bambuser indicated a need for this type of interactivity. Viewers trying to overcome a lack of realtime interaction sent text messages to broadcasters telling them to film certain things. However, at the time most phones required the broadcaster to leave the Bambuser application in order to read the messages, which also meant stopping the broadcast. Soon a chat functionality was designed and implemented. This closer link between viewer and producer resulted in longer broadcasts. As viewers gained the opportunity to take part by typing messages and interact with the producer in real time, the participatory dimension seemed not only to remove the viewer from an observing position but also to increase the broadcasters ambitions and collaborative strategies. Aspects like these manifest the important role of user experience and behavior in the design process (Moggridge 2010). Traditional media organizations and journalists soon picked up on this and began setting up live interviews and to invite the audience to use the chat function to suggest questions. 
Another aspect of this social dimension is the proximity and connectivity to upcoming social networks. The increasing popularity of social networks in 2006 and 2007 worked in the favor of Bambuser. Early in the design process the complex matter of publication platforms revealed itself. A need to address differences in platforms soon became evident. Luckily, real-time publication services such as Twitter, Facebook, and Jaiku were starting to take off at the time. Increasing the ability to easily share broadcasts to and through those services meant that the metadata of the transmission had a social context: an audience could be generated quickly.

With the chat functionality, the rise of social networks provided possibilities for instant feedback exchange between viewer and broadcaster as well as rapid distribution, and hence created opportunities for a larger and more interactive audience that could develop into a critical mass, especially in a context of socio-political turmoil (Krona and Bergknut 2011). This became clear during the uprisings and events in the Arab world in 2011.

\section{Live video verifying events in Tahrir Square}

In this section we discuss empirical events in relation to emerging publics and the implementation of Bambuser in order to enhance the understanding of the use in relation to the design of the service, but also to contextualize it theoretically through the concepts of emerging publics, participation, and public spheres.

On January 25, 2011, the main servers of Bambuser were running high as an increased number of broadcasts were coming out of Egypt. A similar rise of the number of videos had occurred a year before during the election in the country. This time, however, videos showed something different: huge demonstrations in Cairo's Tahrir Square. Traditional journalists were having a hard time trying to keep up with the rapid unfolding development in Egypt. A massive flow of tweets came out of the country with a purpose to convince international media and community of what was taking place. In Stockholm, journalists and editors on the national broadcaster Sveriges Television followed the flood of tweets from Cairo but had a hard time trying to verify the news. Lack of personnel on location made them unsure about what information they should broadcast. When live videos from Bambuser and other platforms reached the media institutions, the verification factor was put in another context. What journalists had failed to verify on Twitter was now unfolding live in front of their eyes. They were witnessing the events in Tahrir Square in real time and from multiple angles, as several Bambuser users were broadcasting with their mobile phones. Shortly thereafter, other international media outlets published news about the massive demonstrations in Cairo.

Journalists using only Twitter or other social networks primarily based on text messages weren't able to verify how many people were in the streets or assess the impact 
of the demonstrations. Videos on YouTube and images on Flickr or Facebook were also hard to validate, since it might as well be old videos or photos of former demonstrations that people were pushing again. Bambuser and online video broadcasting managed to overcome that uncertainty, and the element of live production was important. Through a number of verification points, among other things the integrated chat and the possibilities of both participation and authenticity it generates, the gap between medium and reality decreases. By typing messages into the chat the viewers can verify that something being screened is happening right now. Several Egyptian journalists wrote in the chat of some of the Bambuser broadcasts and asked if it was live and telling broadcasters to for example film to the right at a given point, hence participating themselves in the verification process. One could of course imagine that even though the technology was working fine, it was all a fake with people just acting. But the absurdity of having 100,000 "extras" in a square in Cairo fighting the police, multiplying truth claims and deliberately and strategically trying to obtain a specific purpose, seemed too far-fetched to be taken seriously.

\section{Power and control-communication shutdown}

The demonstrations taking place in January of 2011 in Egypt, and the struggle between citizens and the Mubarak regime, were the results of years of oppression. The digital revolution, to which Bambuser contributed, was certainly a new conceptual understanding of the huge change in power balances surrounding the public sphere and spaces for informing. Through Bambuser the tool to publish anyone's live story of the world was out there through a compatible mobile phone with an Internet connection. The leap was not only technological but also fundamentally changed ownership of the mediated public sphere, something that earlier was limited to major broadcasting companies and public broadcasters. The possibility of owning the tool of broadcasting realtime video changed the balance of power. Governments that earlier owned national TV broadcasting stations, such as the Egyptian government, lost control. In Egypt and in other countries, the relation between the state and citizens has been affected significantly by new information technologies (Osman and Samei 2012).

Power and control over technology and information have always been important dimensions to understand the socio-political implications of technology (Chadwick 2006), and during the Arab Spring the matter was clearly manifested. "Control of ... tools of mass information and persuasion" is, according to Monroe $(1996,8)$, "central to the idea of a commanding state." During the 1990s, with the emergence of satellite network stations such as Al-Jazeera and information technologies, several repressive states in the region already were faced with a dilemma. By stifling new technologies and channels, the regimes risked losing their potential benefits; however, permitting them might threaten the authority of those regimes (Kedzie and Aragon 2012). This 
dilemma is still evident today, when the technological impact continues to increase in speed, reach, and usage.

On June 13, 2010, a lot of Egyptians went into the streets of Cairo to protest police violence that had resulted in the death of the young activist Khaled Saeed a week before. Khaled Mohamed Saeed died under disputed circumstances in the Sidi Gaber area of Alexandria on June 6 after being arrested by Egyptian police. Photos of his disfigured corpse spread throughout online communities and incited outrage over allegations that he was beaten to death by Egyptian security forces. "We are all Khaled Saeed," a Facebook group moderated by Wael Ghonim, brought attention to his death and contributed to growing discontent in the weeks leading up to the Egyptian revolution of 2011.

On June 13 the police started to use excessive force against the protesters. They arrested several hundred. To keeping the information scenario under control, they confiscated protesters' mobile phones and cameras. That day, Ramy Raoof, a well-known human rights lawyer, had equipped his mobile phone with Bambuser. The police erased hundreds of photos and videos from protesters' phones and cameras. On Raoof's phone they found nothing. Assuming that they had control of the information scenario, they denied having used excessive force. But since Raoof's broadcast had not only been broadcast to the Internet in real time but also stored on Bambuser's servers, it was available as evidence. Raoof was able to use the material as evidence against the police in a trial.

${ }^{*}$ A corrected version of this paragraph is available in the end of the chapter (9 January 2017)

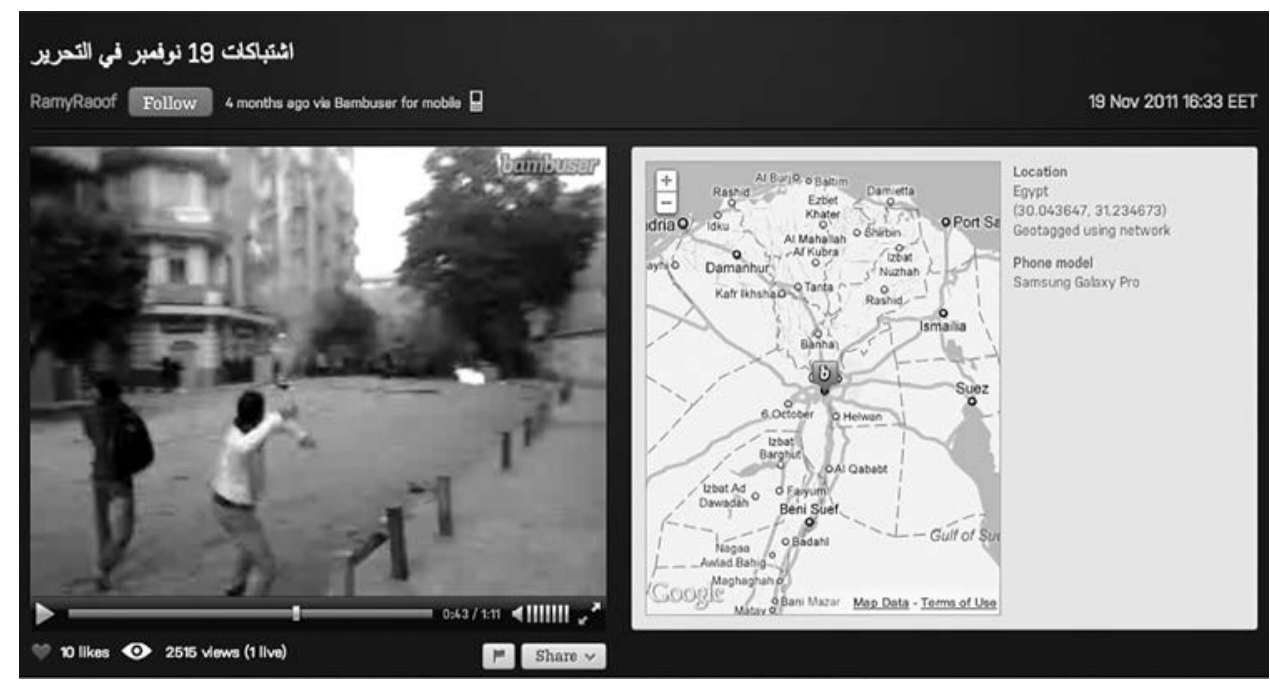

Figure 16.1

A screenshot from user Ramy Raoof showing demonstrations in Egypt. 
Especially in Egypt, this event moved a lot of users toward using Bambuser rather than recording video and then uploading it to YouTube or some other website. The scenario also manifests how Bambuser steps in earlier in the process of recording videos. Whereas YouTube only receives already-recorded files, Bambuser records material in real time and thereby secures live material in a different way.

During the first weeks of the revolution in 2011, during the most intensive protests in Tahrir Square, tweets and other information stopped coming out of Egypt. The country "went dark" for 140-character broadcasted messages, even though Bambuser still received broadcasts. However, soon the service "went dark" in Egypt as the regime initiated a total shutdown of Web services and mobile communications, which became not only symbolic targets for the regime but highly strategic as well. But activists and demonstrators were able to get around the shutdown by combining physical and human interventions with using the technical infrastructure that still was available. One tactic used by activists was to put up tents in Tahrir Square with signs saying "Gathering Pictures and Videos" in order encourage people to compile footage and pictures from demonstrators and upload it online.

In these circumstances, the need for communication solutions, not only in order to get attention from the international community but also to find belonging, community, and identity during hard political and social situations, is evident, and the role of Bambuser is significant in both these aspects. When approaching this development through a sociological narrative of the public sphere, the current role of media technology can advantageously be discussed from a historical perspective. This also sheds light on the power structures of the public sphere as well as the forms of communication within.

\section{Technology and a public sphere in transition}

The conditions for the emergence of a common public space where citizens from different social classes could meet and conduct a dialogue on politics and society were most clearly idealized and described by Jürgen Habermas in The Structural Transformation of the Public Sphere (1962/1991). His ideal of a bourgeois public sphere is dated to eighteenth and nineteenth century Europe, however, as a result of significant changes in the political world, the social world, and the media world, the bourgeois public sphere is deconstructed at the end of the nineteenth century. With a capitalist ideological rampage in much of the Western world, the private becomes subject to economic and political interests. Habermas highlights how the communication context for a dialogic public (private citizens) was broken up and public opinion was turned to the informal opinions and also in large part to the publishing institutions of society that are driven by economic profit maximization. Citizens went from being involved in the shaping of public opinion to spectators to these journalistic institutions of formal opinion making. Even though Habermas has revised these notions during the last decade, the 
argument still reveals a critical attitude toward the modern mass media, their emergence, and their importance.

However, what is interesting in this matter is how media, design, and technological innovation during the last decade or so has altered the participatory form of communication (Rheingold 2002). Citizens' participation and possibilities for generating content within the media sphere is considerably different today and has empowered discourses on new media as a tool for alternative views and expressions toward established political interests (Hachten and Scutton 2006; Hofheinz 2005). In relation to Habermas' sociological perspective on public sphere and transformation, we can also apply the arguments on the current social and political state. Values and properties in the private (warmth, love, intimacy, passion, togetherness, community) are still valued in relation to the impersonal, cold, and aloof public life. A public life that is separate from the intimate sphere, with all the specific core values that it involves, is thus not very attractive. But the development that emerged at the beginning of the twenty-first century has led to what can be argued as a reproduction of core values, a re-introduction of high moral values in the public sphere. Understandings that enable citizens to have control and power over their own persona and role in society, which had previously been firmly linked to the private sphere, have now been incorporated also in the public life. This is a very interesting dimension of late modern society, made even more intricate by a notion that social change is no longer a narrow discussion in and of Westernoriented actors of society but is now a major global concern. Without making excessive claims to universalism or cosmopolitanism, it is necessary to emphasize the trends that appear to lead toward an increased supranational and international consensus on the political conditions that shape our time and history.

The role of media technology must be considered a major factor in this recent development. But instead of just considering technology as an indispensable trigger of a causal chain of events, we here put technology in relation to emerging publics, meaning that the appropriation of technology is considered one of several dimensions contributing to the emergence of new publics and behavioral changes toward more sustainable lifestyles. In the recent events in Egypt and Syria, citizens' use of technology (as opposed to the Habermasian notion of the role of mass media) has altered the form of the public sphere and to some extent revived the bourgeois ideal. Hence, the participatory design of Bambuser and other services is considered a key in trying to re-create an ideal of encounters on similar terms between citizens. New emerging publics, especially in the Arab world, are still far from being characterized by equality with free civic discussions on enhancing democracy, but rather are constituted by an initial phase of gathering around alternative views, expressions, and ideologies, and possibilities to make them visible (Lynch 2011). Hence, yet another shift of power has entered the discussion on democracy and public spheres of society. The diverse control of information, censored as well as user-generated, has changed the rules of engagement. 


\section{Local to public through live interaction}

Aside from the fact that an important piece of information can be instantly moved from its locality to a global awareness, there is also a second effect that such a piece of information can have. Not only is the information available for later use; it is also available as it happens, which means that the public can act upon it. Watching a YouTube video has the inherent limitation that what you see on YouTube has already passed into history. Bambuser, because it operates in real time, opens up the possibility of interacting with, and taking action on the basis of, what is going on in the video.

A couple of months after the Mubarak regime stepped down, there was a demonstration at the Israeli embassy in Egypt against Israel's oppression of the Palestinian people. The police used tear gas, and as the activists tried to escape the gas the military awaited in ambush. Two hundred protesters were arrested. Between the time the police began to order the protesters to hit the ground and when a soldier grabbed him, a protester named Tarek managed to start a Bambuser broadcast with his phone.

The video was very dark during the first 90 seconds and only showed a couple of silhouettes, and the rest was completely black because Tarek put his phone in his chest pocket to hide it from the soldier. But the audio was clear, and what the soldiers and the police said to each other in Arabic couldn't be mistaken. The broadcast went on for nine minutes. By the time Tarek's phone was taken from him, 495 people were listening. Journalists among the viewers of Tarek's broadcast were quick to post the news

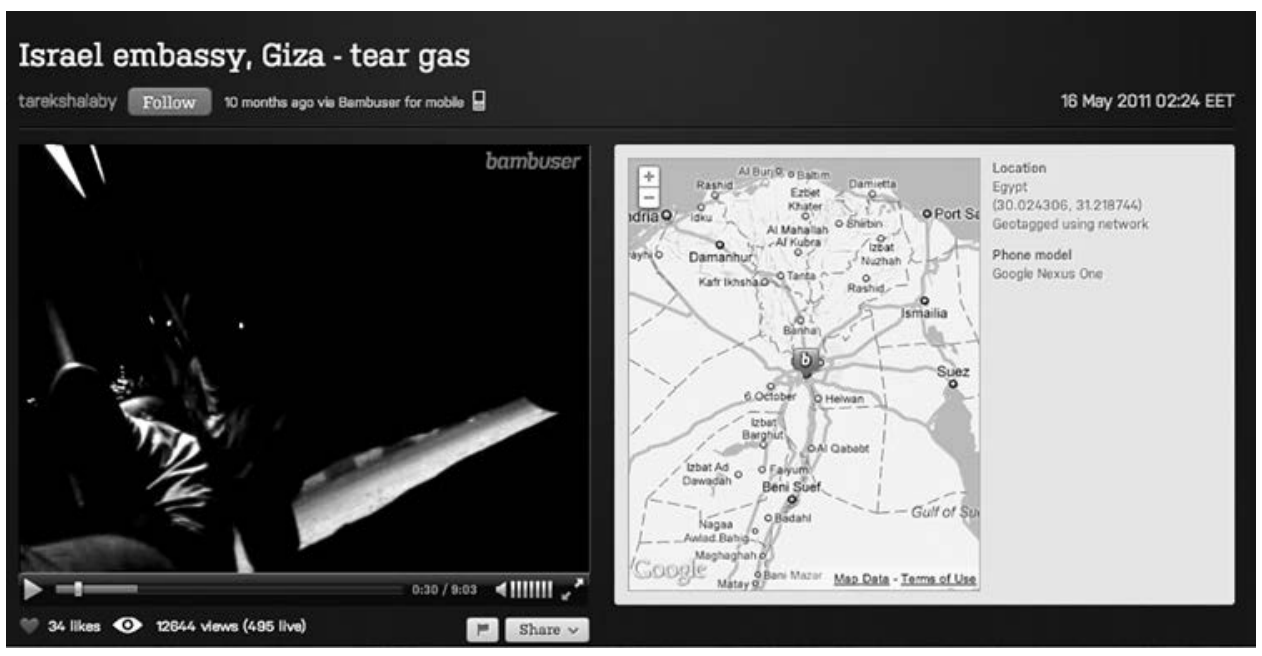

Figure 16.2

A screenshot from user tarekshalaby showing military excessive violence at demonstrations at the Israeli embassy in Egypt. 
on various sites, extending its reach. The broadcast revealed how the military and the police harassed the protesters and raised questions as to why the police and the military were working together, since the military was supposed to be on the peoples' side.

On November 19, 2011, the streets around Tahrir Square became a war zone again after clashes between protesters and police on Mustafa Mahmoud Street. Ramy Raoof went to the front line of the protests, as he had done before, to document any excessive use of force by the police. With his mobile phone broadcasting live, he was shot twice in the stomach area. In the end of the 1.11-minute video one can see protesters throwing rocks at the police, who respond with rubber-covered steel bullets. The final seconds of the video shows Raoof screaming and running. He was lucky to have had several layers of clothes on, so the bullets made two large wounds but didn't pierce his stomach.

Bambuser was also used by the Egyptian police, perhaps in order to reconsider their ways of surveillance. The screenshot reproduced here as figure 16.3 is from a broadcast that was shot by the police.

This type of use illustrates the duality of accessible media technology and emphasizes the paradox mentioned in the introduction to this chapter; a paradox where citizens fight for freedom against a regime and the regime themselves use the same technology to fulfill their purpose. But the use of technology by authoritarian powers can also be more explicit compared to the case above. The next empirical example derives from Syria and problematizes this notion of the downsides of mobile transparency.

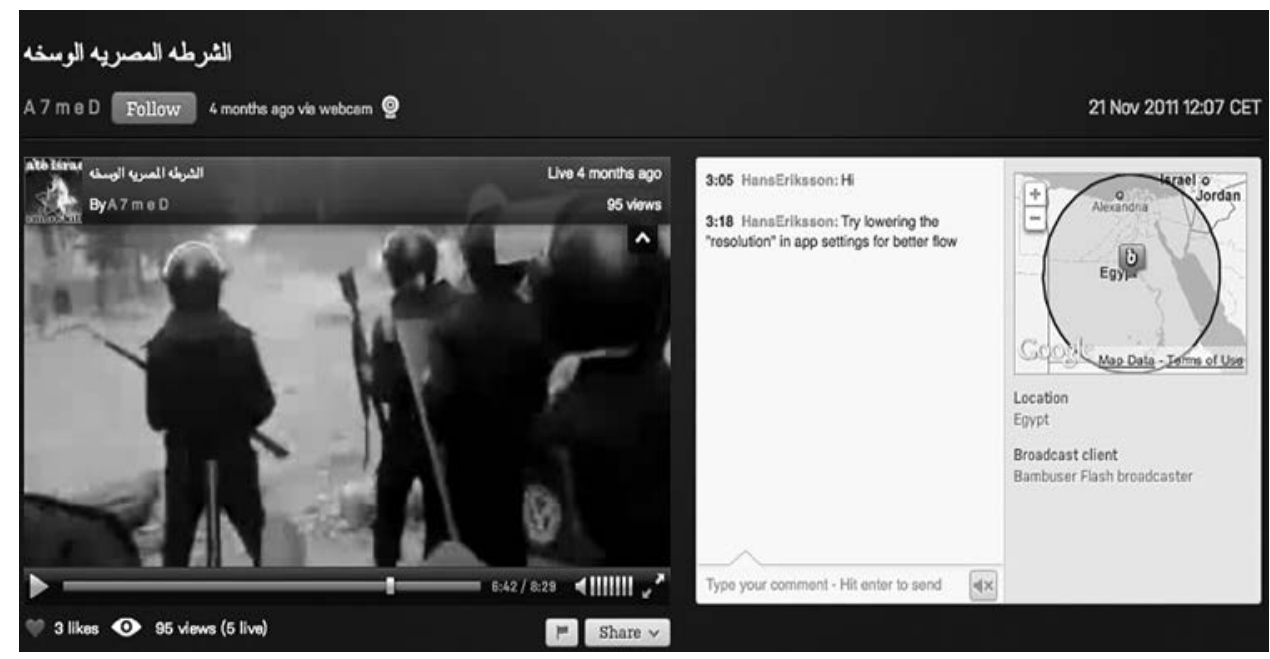

Figure 16.3

A screenshot from user A 7 m e D showing demonstrations in Egypt from the military's perspective. 


\section{Anonymity in the age of transparency}

As the revolutions spread across the Arab countries after starting in Tunisia and Egypt, one of the states in which the aftermath resulted in a civil war is Syria. By early January of 2011, Bambuser.com had already been blocked within the Syrian borders. But during fall that same year, the blockade was seized and slowly an uptake in the amount of videos that were coming out of Syria was observed. The reasons for the blockade remain unclear, but among activists and users rumors went on saying that it was because the Syrian regime was ready to test a new tool for surveillance of Internet usage.

During the fall of 2011 several thousands of videos were broadcast from Syria, the majority of them similar. There was an image of a masked person on a rooftop. Hundreds of people in the street below were protesting with chants and songs. Why the camera wasn't down among the protesters seemed an obvious question, but the simple answer was that if the activists had shown their faces or if the video had shown any details suggesting the location the Syrian regime would have been able to pick individuals out and use the videos as evidence against them. It was important for the protesters to get their message out to the rest of the world, and to tell other Syrians that they are not alone in protesting, without compromising their own safety.

The screenshot reproduced here as figure 16.4 is from a video that came out of Syria during the most intense uprisings. The person setting up the broadcast is up on a rooftop, heavily masked in a scarf and sunglasses, and protesters down on the street are too far away for their identities to be revealed. It is an example of the use of analog

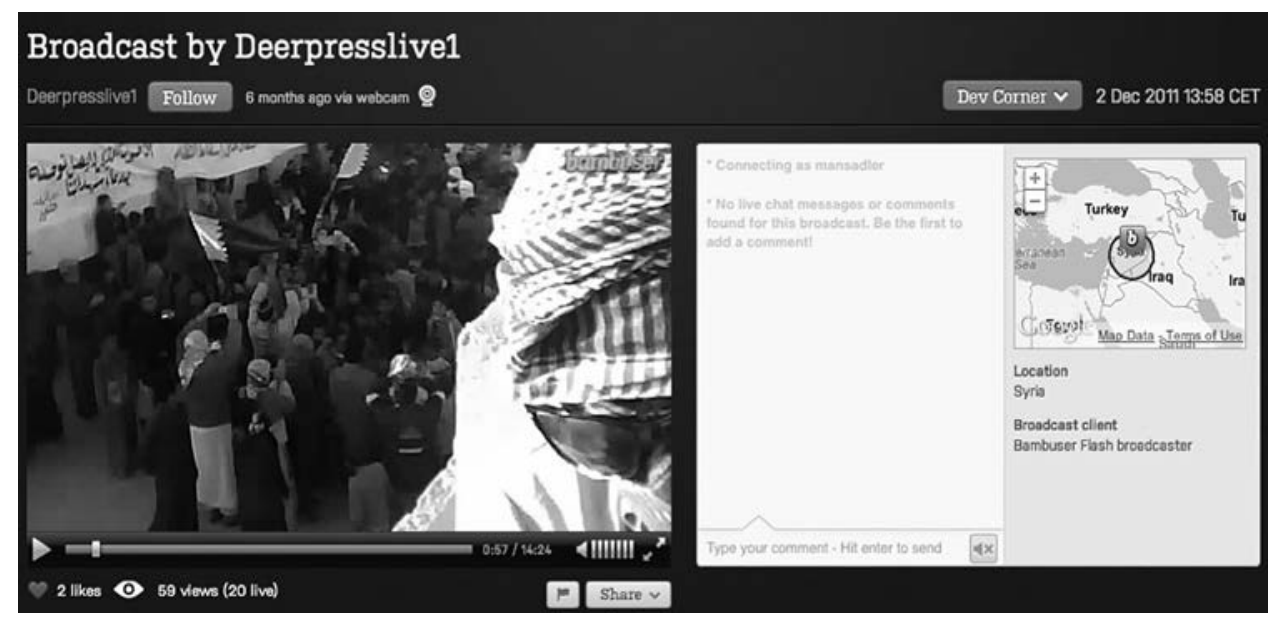

Figure 16.4

A screenshot from user Deerpresslive1 showing demonstrations in Syria. 
strategies to create anonymity. The person in the broadcast is nearly identifiable but has disguised himself with glasses and scarfs. This is an illustrative example of how new and digital technology can be related to traditional and more analog strategies.

In this case, geographical position, both visible marks and the GPS coordinates of the broadcast, is problematized. The Syrian regime seeks to find out where livestreams are coming from. Even if some Syrian activists were using satellite Internet connection to make sure that the regime could not track them down based on cell tower triangulation or IP addresses, they also needed other kinds of methods to come around it. In February 2012 one user of the service started a broadcast from inside Syria showing an enormous plume of smoke coming from a gas pipe that had been bombed by the military. The live broadcast was picked up by Associated Press and then distributed to CNN, BBC, Sky News, and Al-Jazeera. It was re-mediated and broadcast in real time. According to Associated Press, it reached more than a billion viewers. But a couple of hours after this broadcast had been aired on all the major news outlets, Bambuser was blocked in Syria. The Syrian regime then tried to shoot down broadcasters on rooftops by triangulating the positions of broadcasts from well-known buildings that could be seen in the broadcasts.

\section{Finding alternatives}

After the blockade of Bambuser, Syrians kept trying to broadcast real-time video from their country, either through satellite Internet connections or by using SIM cards from Lebanon, Kuwait, or Jordan. Since many of Syria's large cities are close to borders with surrounding countries, several activists were able to use cellular networks in those countries to get around the blockade. That hadn't been possible in Egypt, because Cairo is in the middle of the country. People in Egypt had, however, recorded videos and then driven to the borders to upload them from there.

Realizing how hard it was to stop people from getting live video out of the country, the Syrian regime turned to other measures. One of these was turning the electricity off in opposition areas, making it impossible to charge technological devices and to use them to communicate. Another was to turn the electricity on and off irregularly. Another was to turn it off up to 15 hours a day so no one could charge devices or use the Internet, then to allow high voltage peaks to burn out devices that had been left plugged in.

\section{Summary and concluding discussion}

In any attempt to analyze or discuss the role of new media and technology in relation to political and social change, it is necessary to use specific concepts accurately. The extended use of information and communication technologies in the Middle East and 


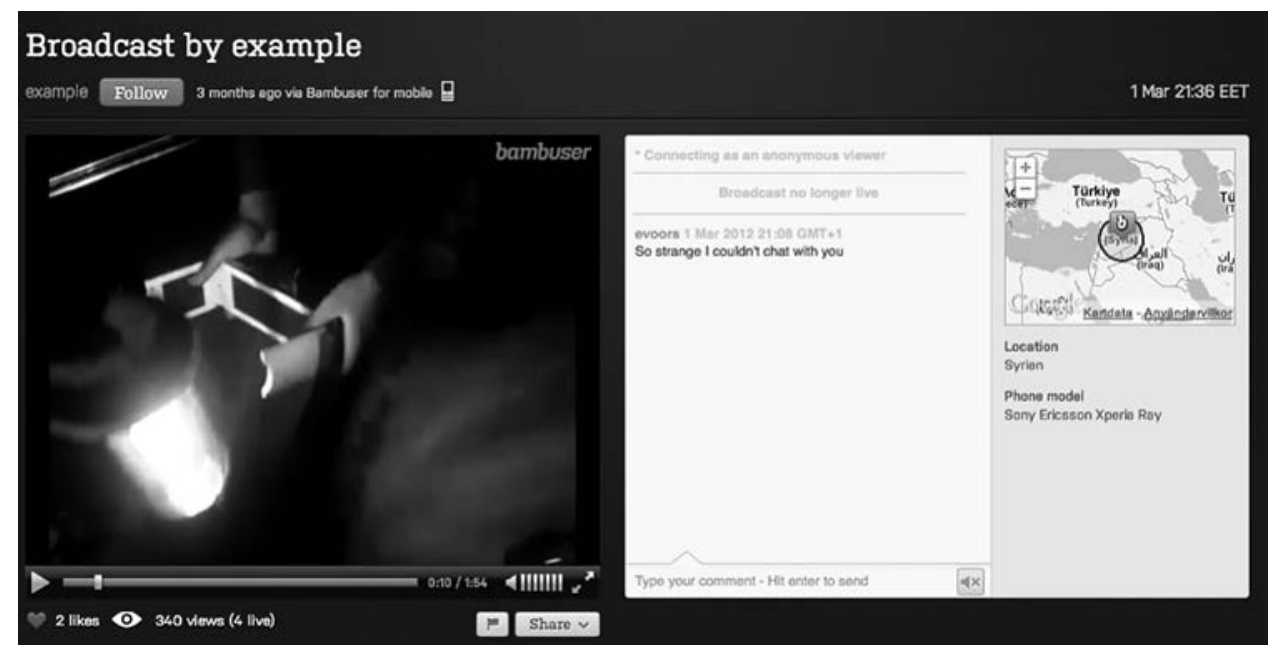

Figure $\mathbf{1 6 . 5}$

A screenshot from user example showing Syrian activists shining a gas lamp on a panel of solar chargers in order to charge cell phones during an electrical blackout.

Northern Africa has, at least during the last decade, been surrounded by an intellectual debate about contributing to the achievement of sociopolitical changes (Hofheinz 2011). However, it is our belief that scholarly contributions sometimes seem to focus explicitly on actual political change and politics, rather than critically highlight how new media can embrace, transform, and create dynamics in Arab public opinion, civic life, and political activism (Lynch 2011). We believe this focus limits the perspective in efforts of comprehending the role of media technology in sociopolitical change. Instead we have argued for a notion of technology as a mean to first and foremost, in the process of use, change people's awareness and by extension vitalize a public debate on social and political issues. Changes in continuous politics must be regarded as secondary in this process.

The purpose of this chapter is to describe, both theoretically and empirically, the role of media technology in peoples' struggle to achieve political and social change in Egypt and Syria during 2011 and 2012. Our main argument in this story has been that technologies hold different grades of significance depending on design processes, user involvement, and social implications. The case of Bambuser, an Internet and mobile application service that allows anyone to broadcast online video at any time for free, has been the center of attention. The service itself was designed with a specific purpose to democratize a technology and find answers to questions regarding what is important for people to broadcast and to view. This is here considered the first level of understanding the relation between user and the specific technology. The second level turns 
to the wider sociopolitical implications of the use. In a context of disturbing political contexts, as during political unrest in Egypt and Syria, what significance does the possibility to broadcast moving images have for activists and for political regimes? In order to find answers to these questions, we turned to a theoretical toolbox of public spheres and a perspective of social shaping of technology. The first one helped to conceive the retrospective importance of participatory design in the phases of development as well as implementation of technology, enhancing the traditional conception of public sphere. Initial notions on what Bambuser could and should be in relation to what it became, hold both similarities and differences. The vision that the service would help to democratize a technology, making it accessible for anyone with a mobile phone, not only stands but has also contributed to larger political implications in the specific region. Aspects of democratization in the design manifested itself in the continuous sensibility to user reactions and strategic development of enhancing the user experience. Designing Bambuser as a service providing both unique user experiences in real time as well as opportunity to affect political and social conditions enhances the interconnectivity between participatory design and communication. From the theoretical horizons applied in this chapter we argue that Bambuser, and other similar services, constitute a form of resistance against and a natural result of rationalization processes that for decades have signified political and social life, but also to some extent aspects of design and innovation. But resistance against what?

The need for formulating a theory of political transformation has never been more evident, due to the current interconnections between particular technological, political, and social concerns. In the reasoning of Andrew Feenberg (2002), as he states that there are ways of rationalizing society that democratize rather than centralize control, lies arguments on that modernity is characterized by an extent of rationality and therefore it takes oppositional and alternative rationalization processes to also reproduce alternative modernities. The type of rationality that has shaped society in general has also embodied the technological design of our days. And, when speaking of democratizing technology, it is basically a process of expanding the technological design in order to integrate oppositional (alternative) voices and interests. Originally we can find the predecessor for this theoretical trajectory as far back as to Max Weber's sociological theory of modernity, in which he argues for capitalism's focus on formal rationality, leading up to a differentiation between technology and social spheres of society. In other words, the emerging modernity has throughout history proved to be achieved at the expense of a transformation based on moving away from a private sphere (substantive relations) to a public sphere of impersonal and formal relations of modernity. A capitalist society demands this shift and adopts formal rationality to expand production and profit. Just as Theodor Adorno and Max Horkheimer argue on the rationalization of cultural industries, within the legacy of the Frankfurt Institute, one can apply the discourse of rationality in relation to this Weberian theoretical framework (see Adorno and Horkheimer 1947). 
The rationalization of society can take different forms of manifestation, including technological processes. Bambuser, because it challenges former structures and enables alternative voices and marginalized groups to be heard (Tufte and Mefalopulos 2009), can be considered an alternative form of expression. The progressive view on both technology and citizens' use of it also encapsulates a more balanced approach to the sociological implications of media technology in late modern society. Even if services like Bambuser are to extend the public sphere and put new rules of engagement in it, the same technological impact must be framed toward related critical dimensions for this extension. Habermas' (1962/1991) ideal of a social and public sphere, in which participation and deliberation were to be equal, have in recent years been discussed by theorizing on Internet as forum for this equality, signified by free speech and accessibility. However this notion is easily challenged due to hierarchical structures and resource (both human and infrastructural) inequality. In this chapter we have outlined both the challenges associated with digital divides and possible contributions to decreasing it. Aspects of democratizing a technology, as the case of Bambuser illustrates, is considered a realm of this process. The technology itself doesn't achieve democratic reforms or political change but can rather trigger citizens in terms of awareness, community building, organization, and mobilization (Krona and Bergknut 2011). And when approaching this from the perspective of participatory design, hence involving users on several levels, the implementation of the technology may have wider democratic impact in comparison with top-down design and implementation as earlier media technology development bear witness of.

However, the progressive features of this development simultaneously lead to necessities of critical reflection on the both proven and hypothetical downsides. The Arab uprisings showed that the use of video as a monitoring tool has shifted decisively. Throughout the 1990s and 2000s, civil libertarians worried about governments and corporations slapping up surveillance cameras on public places. The fear was that they would be used as tools of oppression.

But now those tools are being democratized, as we are witnessing an emerging culture of "sousveillance"; providing opportunities for emerging new publics. The difference from before is that technology opens up for the monitoring function to be offered to more stakeholders, that is to say that there are no longer only states or regimes that monitors its citizens in various ways, but also citizens who can monitor their oppressors. The Orwellian Big Brother-society is though certainly nothing new. Jeremy Bentham's historical consideration of the panopticon and a social system where the monitoring and observation made people aware of the fact that they might be monitored, although didn't know. This impact was found, according to Foucault, to implicate that monitors through the both symbolic and pragmatic use of the panopticon within a specific social context (such as a prison) could influence people to think and act in a certain way based on the fear that they could be monitored, thus given rise to 
opportunities for social control. The panopticon was part of the industrial revolution which embraced a need for industrial monitoring where owners and other people in power could monitor public places, not just prisons and factories, or, as Foucault (1980, 71) put it, "panopticism was a technological invention in the order of power, comparable with the steam engine."

Since then the monitoring devices have been more integrated with everyday life and currently also been put in the hands of everyone. "Sousveillance" is the monitoring of events not by those above but by citizens, from below. Steve Mann, a pioneer in wearable computing at the University of Toronto, coined the neologism and in the 1990s he rigged a head-mounted camera to broadcast images online and found that it was great for documenting everyday malfeasance, like electrical-code violations. He also discovered that it made security guards uneasy. They would ask him to remove the camera and when he refused they would escort him away or simply tackle him.

The perhaps most famous example of this feature could be when a Los Angeles resident named George Holliday videotaped police officers assaulting Rodney King in 1991 after stopping him for a traffic violation. From the voyeuristic images a debate on police brutality emerged and the officers were put on trial. The example manifests an unplanned sousveillance, opposite to the cases being put forward in this chapter on the Arab Spring. In this latter case the technology is primarily used by citizens through a conscious implementation in real time often with specific purposes. But the purposes aside, the current society being balanced between surveillance and sousveillance technology is no longer a utopian vision but an implemented reality. Since the attempts from regimes in Egypt, Syria, and other Arab countries to control the technology and integrate the same technology that has empowered citizens to resist and mobilize protests in their own operations, present-day society must be considered technocratic in the sense that control and strategic use of technology during these circumstances is an extremely important feature for stakeholders on both sides. The struggle over information control has been going on for a long time but currently we are witnessing how contextual power balances have been evened out, much due to the technological design and innovation supporting democracy, citizens, and free speech. The future is not written but there is no reason to believe that the technological development, especially within the media sector, will stop from further rise according to peoples' struggle for freedom and participation in the public spheres of society.

\section{References}

Adorno, Theodor, and Max Horkheimer. 1947. Dialectic of Enlightenment. Fischer.

Boczkowski, Pablo. J. 2004. Digitizing the News: Innovation in Online Newspapers. MIT Press.

Briggs, Asa, and Peter Burke. 2009. A Social History of the Media. Polity. 
Chadwick, Andrew. 2006. Internet Politics: States, Citizens and New Communication Technologies. Oxford University Press.

Chapman, Jane. 2005. Comparative Media History. Polity.

Dahlgren, Peter. 2009. Media and Political Engagement: Citizens, Communication and Democracy. Cambridge University Press.

Feenberg, Andrew. 2002. Transforming Technology: A Critical Theory Revisited. Oxford University Press.

Foucault, Michel. 1980. Power/Knowledge: Selected Interviews and Other Writings, 1972-1977. Harvester.

Habermas, Jürgen. 1962/1991. The Structural Transformation of the Public Sphere. MIT Press.

Hachten, William, and James F Scutton. 2006. The World News Prism-Global Information in a Satellite Age, seventh edition. Blackwell.

Hofheinz, Albrecht. 2005. The Internet in the Arab World: Playground for Political Liberalization. Internationale Politik und Gesellschaft 3: 78-96.

Hofheinz, Albrecht. 2011. Nextopia? Beyond Revolution 2.0. International Journal of Communication 5: 1417-1434.

Howard, Philip. N. 2011. The Digital Origins of Dictatorship and Democracy: Information Technology and Political Islam. Oxford University Press.

Kedzie, Christopher, and Janni Aragon. 2012. Coincident Revolutions and the Dictator's Dilemma: Thoughts on Communication and Democratization. In Technology, Development and Democracy: International Conflict and Cooperation in the Information Age, ed. J Allison. SUNY Press.

Krona, Michael, and Amanda Bergknut. 2011. Social Media Mobilization in Arab Nations during the Uprising of 2011. Paper presented at annual Nordmedia Conference, Akyreyri, Iceland.

Lievrouw, Leah, and Sonia Livingstone, eds. 2006. The Handbook of New Media. Sage.

Löwgren, Jonas, and Bo Reimer. 2013. Collaborative Media: Production, Consumption, and Design Interventions. MIT Press.

Lynch, Mark. 2011. After Egypt: The Limits and Promise of Online Challenges to the Authoritarian Arab State. Perspectives on Politics 9 (2): 301-310.

Moggridge, Bill. 2010. Designing Interactions. MIT Press.

Monroe, Edwin P. 1996. Television, the Public Sphere and National Identity. Oxford University Press. Osman, Amr, and Marwa A. Samei. 2012. The Media and the Making of the 2011 Egyptian Revolution. Global Media Journal (German Edition) 2(1): 1-19.

Rheingold, Howard. 2002. Smart Mobs: The Next Social Revolution. Perseus. 
Riggins, Frederick, and Sanjeev Dewan. 2005. The Digital Divide: Current and Future Research Directions. Journal of the Association for Information Systems 6 (12): 298-337.

Thompson, John. B. 1995. The Media and Modernity: A Social Theory of The Media. Polity.

Tufte, Thomas, and Paolo Mefalopulos. 2009. Participatory Communication: A Practical Guide. World Bank.

van Dijk, Jan A. G. M. 2005. The Deepening Divide—Inequality in the Information Society. Sage.

${ }^{*}$ Correction to page 331 (made on 9 January 2017) - On June 13 the police started to use excessive force against the protesters, and also arresting some of them. To make sure they kept the information scenario under control, they confiscated some protesters' mobile phones and cameras. That day, Ramy Raoof, a well-known technologist in the human rights domain, had equipped his mobile phone with the Bambuser application. The police erased hundreds of photos and videos from protesters' confiscated phones and cameras. But Raoof s footage of the events was however secure from that scenario, even though his phone never got confiscated in this case. Assuming that they had control of the information scenario, the police denied having used excessive force in the aftermath. But since Raoof s broadcast had not only been broadcast to the Internet in real time but also stored on Bambuser's servers, it was available as obvious proof of the excessive force for the public to see for themselves. 
